\title{
Water Hammer Control Using Additional Branched HDPE Pipe
}

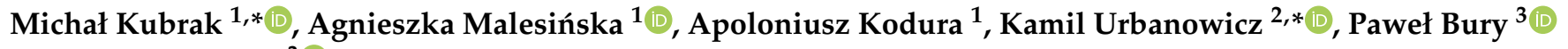 \\ and Michał Stosiak ${ }^{3}$ iD \\ 1 Faculty of Building Services, Hydro and Environmental Engineering, Warsaw University of Technology, \\ 00-653 Warsaw, Poland; agnieszka.malesinska@pw.edu.pl (A.M.); apoloniusz.kodura@pw.edu.pl (A.K.) \\ 2 Department of Mechanical Engineering and Mechatronics, West Pomeranian University of Technology, \\ 70-310 Szczecin, Poland \\ 3 Department of Technical Systems Operation and Maintenance, Faculty of Mechanical Engineering, \\ Wroclaw University of Technology, 50-371 Wroclaw, Poland; pawel.bury@pwr.edu.pl (P.B.); \\ michal.stosiak@pwr.edu.pl (M.S.) \\ * Correspondence: michal.kubrak@pw.edu.pl (M.K.); kamil.urbanowicz@zut.edu.pl (K.U.)
}

check for updates

Citation: Kubrak, M.; Malesińska, A.; Kodura, A.; Urbanowicz, K.; Bury, P.; Stosiak, M. Water Hammer Control Using Additional Branched HDPE Pipe. Energies 2021, 14, 8008. https://doi.org/10.3390/en14238008

Academic Editors: Sebastian Muntean, Pavel Rudolf, Giovanna Cavazzini, Eduard Doujak and Pål-Tore Selbo Storli

Received: 29 October 2021

Accepted: 22 November 2021

Published: 30 November 2021

Publisher's Note: MDPI stays neutral with regard to jurisdictional claims in published maps and institutional affiliations.

\section{Copyright: (C) 2021 by the authors.} Licensee MDPI, Basel, Switzerland. This article is an open access article distributed under the terms and conditions of the Creative Commons Attribution (CC BY) license (https:// creativecommons.org/licenses/by/ $4.0 /)$.

\begin{abstract}
In pressurised pipeline systems, various water hammer events commonly occur. This phenomenon can cause extensive damage or even lead to a failure of the pumping system. The aim of this work is to experimentally re-examine the possibility of using an additional polymeric pipe, installed at the downstream end of the main pipeline, to control water hammer. A previous study on this topic investigated additional polymeric pipes connected to the hydraulic system with a short joint section of the same diameter as the main pipeline. In the current research, a different method of including an additional pipe was considered which involved connecting it with a pipe of a smaller diameter than the main pipeline. Three additional HDPE pipes, with different volumes, were investigated. The performance of the devices was studied for hydraulic transients induced by both rapid and slow, manual valve closures. Experimental results show that the additional polymeric pipe can provide significant pressure surge damping during rapid water hammer events. As the valve closing time lengthens, the influence of the additional pipe on the maximum pressure increase is reduced. The additional HDPE pipe does not provide notable protection against hydraulic transients induced by slow valve closure in terms of reducing the first pressure peak. No relationship between the volume of the additional pipe and the damping properties was noticed. The observed pressure oscillations were used to evaluate a one-dimensional numerical model, in which an additional pipe is described as a lumped parameter of the system. The viscoelastic properties of the device were included using the one element Kelvin-Voigt model. Transient flow equations were solved with the implicit method of characteristics. Calculation results demonstrate that this approach allows one to reasonably reproduce unsteady flow oscillations registered during experiments in terms of the maximum pressure increase and pressure wave oscillation period.
\end{abstract}

Keywords: water hammer control; hydraulic transients; viscoelasticity; additional pipe; branched pipe; numerical simulation

\section{Introduction}

Water hammer is an undesirable pressure surge caused by a sudden change in flow velocity. Among engineers involved in designing pipelines, it is well-known that this phenomenon can cause extensive damage or even lead to a failure of the pumping system [1,2]. In practice, it is impossible to completely avoid the occurrence of severe hydraulic transients. Pressure pipeline systems are constantly subjected to flow disturbances and, thus, water hammer events commonly occur. For this reason, the efforts of many engineers and researchers are focused on developing effective methods to mitigate the destructive effects of this phenomenon.

One of the common strategies to manage extreme pressures involves optimising the operating procedures. Bazargan-Lari et al. [3] studied an optimal valve closing procedure 
for real time pressure control in pipes. Wan et al. [4] showed that it is significant to set a reasonable operational time difference in pump-valve systems in order to prevent backflow, reverse rotation, and overpressure. Optimal closure laws were also studied in pumpturbines systems by Yu et al. [5], Zhou et al. [6] and Pérez-Sánchez et al. [7]. This problem is also relevant for transient flow of compressible fluids. Subani et al. [8] analysed the flow of a hydrogen-natural gas mixture to determine relationship between pressure waves and different modes of closing and opening of valves.

Another method of protecting pipelines against water hammer events is to install surge control equipment at the transient-sensitive region of the hydraulic system [9]. The following devices are commonly employed to reduce dangerous pressure rises [10]: air chambers, surge tanks, flywheels, air inlet valves and pressure relief or pressure-regulating valves. Stephenson [11] developed a simple guide for the correct sizing of air vessels. The optimal selection of air chamber size was numerically and experimentally studied by Kim et al. [12]. The performance of modern water hammer control systems involving surge tanks was analysed by Wan et al. in $[13,14]$. The influence of surge tanks on hydropower plants was studied by Riasi et al. [15] and Vereide et al. [16]. Research on the behaviour of air valves during hydraulic transients by Balacco et al. [17] suggested that these devices should be designed using experimental investigations. The basic principles in designing pressure relief valves were described by Zhang et al. [18]. Kim and Kim [19] studied the performance of pressure relief valves in cavitation condition. All of the mentioned devices are usually costly. Several recent studies have been carried out on the influence of a combination of simple water hammer control devices, to mitigate hydraulic transients. Bettaieb and Haj Taieb [20] analysed the control of pressure oscillations by means of simple and economic devices. Mery et al. [21] conducted experiments revealing the effect of combining different water hammer control techniques on pressure waves.

Another tactic used to attenuate pressure waves is to modify the pipeline system in order to lower its effective bulk elasticity modulus. This can be performed by inserting a flexible tube into the pipeline [22], installing additional highly-deformable pipes in a pumping system, adding an in-line polymeric short section, branched penstock or by combining these techniques. Kubrak and Kodura [23] used a flexible gas-inflated tube inserted into the steel pipeline to control unsteady pressure oscillations. The experimental and numerical study performed by Pezzinga and Scandura [24] and Pezzinga [25] revealed that the ability of the additional polymeric pipe to dampen pressure waves depends mainly on the ratio between the volume of the device and that of the network system. The performance of redesigning existing steel pipelines to control severe pressure waves was investigated by Triki [26-29] who revealed that this technique may significantly enhance the reliability of hydraulic systems.

The aim of this research is to re-examine the possibility of using additional branched HDPE pipes to control water hammer in a steel pipeline. Previous papers on this topic [24,25] considered additional pipes connected to the hydraulic system with a short joint section of the same diameter as the main pipeline. This may not often be feasible for existing pipeline systems. To overcome this shortcoming, this paper presents a new approach to include additional polymeric pipe in the steel pipeline system, in order to mitigate high pressures. Furthermore, most experimental studies only focused on water hammer events initiated by rapid valve closure. Current research also examines the performance of the additional pipe during hydraulic transients induced with slow valve manoeuvring.

This paper is divided into six sections. Section 2 provides a brief mathematical description of unsteady flow in a pipeline system with the additional pipe installed. In Section 3, the experimental study is presented. The analysis of experimental results is Section 5. Section 5 examines numerical calculations simulating water hammer events in the pipeline system, with an additional pipe, induced by an instantaneous valve closure. Our conclusions are drawn in the final section. The flowchart of this study is presented in Figure 1. 


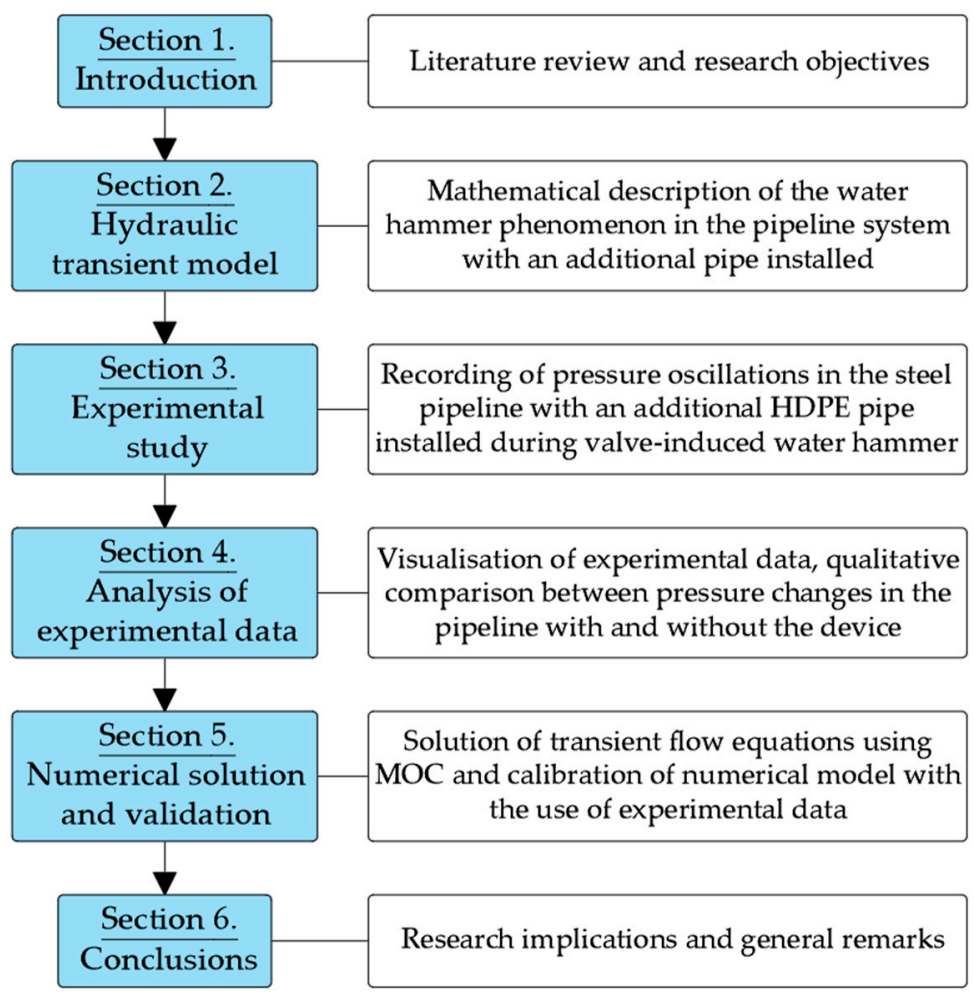

Figure 1. Research flowchart.

\section{Hydraulic Transient Model}

Transient flow equations result from the conditions of continuity and dynamic equilibrium and can be expressed in the following form:

$$
\begin{gathered}
\frac{\partial H}{\partial t}+\frac{c^{2}}{g A} \frac{\partial Q}{\partial x}=0 \\
\frac{\partial Q}{\partial t}+g A \frac{\partial H}{\partial x}+\frac{f Q|Q|}{2 D A}=0
\end{gathered}
$$

where $f$ is the friction factor $(-), c$ is the pressure wave velocity $(\mathrm{m} / \mathrm{s}), H$ is the piezometric head $(\mathrm{m}), Q$ is the discharge $\left(\mathrm{m}^{3} / \mathrm{s}\right), g$ is the gravity acceleration $\left(\mathrm{m} / \mathrm{s}^{2}\right), x$ is the space coordinate (m), $t$ is time (s) and $A$ is the cross-sectional area of the pipe $\left(\mathrm{m}^{2}\right)$.

In order to take into account the influence of the additional pipe in the unsteady flow equations, a simplified model was used. It involves considering an additional pipe as a lumped parameter [24]. This approach allows for significant simplifications as the unsteady flow parameters in the additional pipe ( $Q$ and $H$ ) are only calculated at one spatial point. In this model, frictional losses and the inertia term in Equation (1) are neglected and a constant value of pressure is assumed in the additional pipe. This is acceptable for cases in which the velocity of the pressure wave in the additional pipe is negligible, in comparison with the period of the water hammer phenomenon in the main pipeline. The presented model is valid for pressure oscillations induced by instantaneous valve manoeuvring. The boundary condition of the device must satisfy mass conservation and it expresses the connection between the discharge and the deformation of the additional pipe, as well as the water inside it. By assuming that the additional pipe is fabricated of the elastic material, the boundary condition is:

$$
Q=-\frac{g}{c_{A P}^{2}} \frac{d H}{d t} W_{A P}
$$

where $c_{A P}$ is the pressure wave velocity in the additional pipe $(\mathrm{m} / \mathrm{s})$ and $W_{A P}$ is the volume of the additional pipe $\left(\mathrm{m}^{3}\right)$. 
If the additional pipe is fabricated of polymers, its viscoelastic behaviour must be taken into account and the boundary condition takes the following form:

$$
Q=-\left(2 \frac{d \varepsilon}{d t}+\frac{g}{c_{A P}^{2}} \frac{d H}{d t}\right) W_{A P}
$$

where $\varepsilon$ is the unit strain in the additional pipe wall (-).

The mathematical description of the viscoelastic behaviour of pipe-wall material during hydraulic transients was thoroughly derived in [30-32]. Here, only crucial equations are given, for brevity. The distinctive feature of viscoelastic materials is that their total strain can be expressed as the sum of instantaneous and retarded strains:

$$
\varepsilon=\varepsilon_{0}+\varepsilon_{r}
$$

where $\varepsilon_{0}$ is the instantaneous (elastic) strain and $\varepsilon_{r}$ is the retarded strain (-).

According to the Boltzmann superposition principle, the total stress can be expressed as:

$$
\varepsilon(t)=J_{0} \sigma(t)+\int_{0}^{t} \sigma\left(t-t^{\prime}\right) \frac{\partial J\left(t^{\prime}\right)}{\partial t^{\prime}} d t^{\prime}
$$

where $J_{0}$ is the instantaneous creep compliance $\left(\mathrm{Pa}^{-1}\right), J\left(t^{\prime}\right)$ is the creep function at $t^{\prime}\left(\mathrm{Pa}^{-1}\right)$ time and $\sigma$ is the stress $(\mathrm{Pa})$.

It is assumed that the total circumferential strain is:

$$
\varepsilon=\frac{D_{A P}-D_{A P 0}}{D_{A P 0}}
$$

where $D_{A P}$ is the inner diameter of the additional pipe at time $\mathrm{t}(\mathrm{m})$ and $D_{A P 0}$ is the inner diameter of the additional pipe in steady (pre-transient) flow $(\mathrm{m})$.

Assuming that the pipe material is homogenous, isotropic, has linear viscoelastic behaviour for small strains, and its Poisson's ratio is constant, the total circumferential strain is given by:

$$
\varepsilon(t)=\frac{\alpha_{0}}{2 S_{A P 0}}\left[p(t)-p_{0}\right] J_{0}+\int_{0}^{t} \frac{\alpha\left(t-t^{\prime}\right) D_{A P}\left(t-t^{\prime}\right)}{2 s_{A P}\left(t-t^{\prime}\right)}\left[p\left(t-t^{\prime}\right)-p_{0}\right] \frac{\partial J\left(t^{\prime}\right)}{\partial t^{\prime}} d t^{\prime}
$$

where $p(\mathrm{t})$ is the pressure at time $t(\mathrm{~Pa}), p_{0}$ is the initial pressure, $J(t)$ is the creep compliance at time $t(\mathrm{~Pa}), S_{A P}$ is the additional pipe wall thickness $(\mathrm{m})$ and $\alpha$ is the dimensionless parameter (dependent on the additional pipe diameter and constraints).

If the material is viscoelastic, its response to the applied stress can be described as the behaviour of a combination of elastic springs and viscous dashpots, which constitutes the so-called modified Kelvin-Voigt model. The creep function describing the viscoelastic properties of the $n$ Kelvin-Voigt elements is:

$$
J(t)=\sum_{i=1}^{n} J_{i}\left(1-e^{-\frac{t}{\tau_{i}}}\right)
$$

where $i$ is the number of a single Kelvin-Voigt element (-), and $n$ is the total number of Kelvin-Voigt elements (-).

It should be noted that Equations (3) and (4) were related to the control of a water hammer negative-surge framework. In such cases, in the initial phase of unsteady pressure oscillations, water discharges out of the additional pipe. Hence, the right-hand side of Equations (3) and (4) have a negative sign. In this research, the performance of an additional pipe was tested during positively induced pressure surges, which caused a 
certain volume of water to initially flow into the device. Therefore, the boundary condition for the viscoelastic additional pipe is:

$$
Q=\left(2 \frac{d \varepsilon}{d t}+\frac{g}{c_{A P}^{2}} \frac{d H}{d t}\right) W_{A P}
$$

The differential Equation (10) must be simultaneously considered with the retarded strain component, described by Equation (8).

\section{Experimental Study}

The main goal of this experimental study was to record pressure changes during the valve-induced water hammer phenomenon in a steel pipeline with an additional HDPE pipe installed. The experiments were conducted on a simple pressure tank-pipeline stand, the diagram of which is presented in Figure 2.

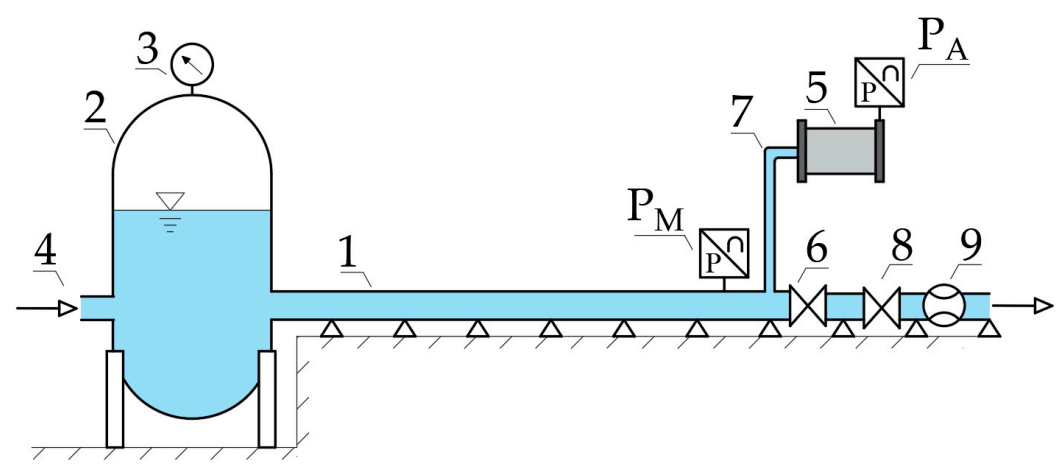

Figure 2. Experimental setup: 1-main pipeline, 2-pressure tank, 3-Bourdon pressure gauge, 4-water supply system, 5-additional pipe, 6-valve initiating transient flow, 7-connecting pipe, 8 -regulating valve, 9 -inductive flow meter, $\mathrm{P}_{\mathrm{M}}$ - pressure sensor installed in main pipeline $\mathrm{P}_{\mathrm{A}}-$ pressure sensor installed in additional pipe.

During the experiments, the pipeline (labelled 1 in Figure 2) was fed from a pressure tank (labelled 2 in Figure 2) with a Bourdon pressure gauge (labelled 3 in Figure 2) connected into the water supply system (labelled 4 in Figure 2). An additional HDPE pipe (labelled 5 in Figure 2) was installed at the downstream end of the main pipeline just before the valve which initiated the water hammer phenomenon (labelled 6 in Figure 2). The method of connecting an additional pipe (AP) to the steel main pipeline (MP) requires additional comment. In previous studies on this topic [24,25], the connecting pipe had the same diameter as the MP. However, for existing pipelines, this method of connection of the device seems impractical. In the current research, the MP is smaller in diameter than the AP. For this reason, in all experiments, the AP was connected to the MP with an L-shape bend copper pipe with an internal diameter of $12 \mathrm{~mm}$ and a total length of $0.61 \mathrm{~m}$ (labelled 7 in Figure 1).

The steel MP with an inner diameter of $0.053 \mathrm{~m}$ was $48 \mathrm{~m}$ long and consisted of 24 sections rigidly connected to each other and fixed to the floor. Pressure changes were measured with the piezo-resistive sensors located at the end of the steel pipeline (labelled $\mathrm{P}_{\mathrm{M}}$ in Figure 2) and in the AP (labelled $\mathrm{P}_{\mathrm{A}}$ in Figure 2). Pressure sensors were connected to a laptop through a DAQ device with the dedicated LabView program. The valve, which induced a pressure surge, was equipped with a system which was able to register its opening angle as a function of time. This allowed the measurement of time of the valve closure. In order to shorten the valve's manoeuvring time, it was partially closed during steady flow. Transient flow was induced by manual valve closing. The volumetric flow rate was regulated with a valve (labelled 8 in Figure 2) and measured with an inductive flow meter (labelled 9 in Figure 2). In order to assess the influence of volume of the AP on 
the ability to dampen pressure waves, three additional HDPE pipes of different lengths (with the same internal diameters and wall thicknesses) were used in the experiments. The material parameters of the APs are summarised in Table 1.

Table 1. Parameters of the additional pipes used in experiments.

\begin{tabular}{cccccc}
\hline \multirow{2}{*}{ AP Number } & $\begin{array}{c}\boldsymbol{L}_{A P} \\
{[\mathrm{~m}]}\end{array}$ & $\begin{array}{c}\boldsymbol{D}_{A P} \\
{[\mathrm{~m}]}\end{array}$ & $\begin{array}{c}\boldsymbol{S}_{A P} \\
{[\mathrm{~m}]}\end{array}$ & $\begin{array}{c}W_{A P} \\
{\left[\mathbf{m}^{3}\right]}\end{array}$ & $\begin{array}{c}W_{A P} / W_{M P} \\
{[-]}\end{array}$ \\
\hline 1 & 0.40 & 0.086 & 0.012 & 0.0023 & 0.02 \\
2 & 0.80 & 0.086 & 0.012 & 0.0046 & 0.04 \\
3 & 1.50 & 0.086 & 0.012 & 0.0087 & 0.08 \\
\hline
\end{tabular}

$L_{A P}$-length of the additional pipe, $D_{A P}$-inner diameter of the additional pipe, $S_{A P}$-additional pipe wall thickness, $W_{A P}$-volume of the additional pipe, and $W_{M P}$-volume of the main pipeline.

All three additional pipes used in the experiments are shown in Figure 3a, and the individual elements of each device are presented on the example of AP no. 1 in Figure 3b.

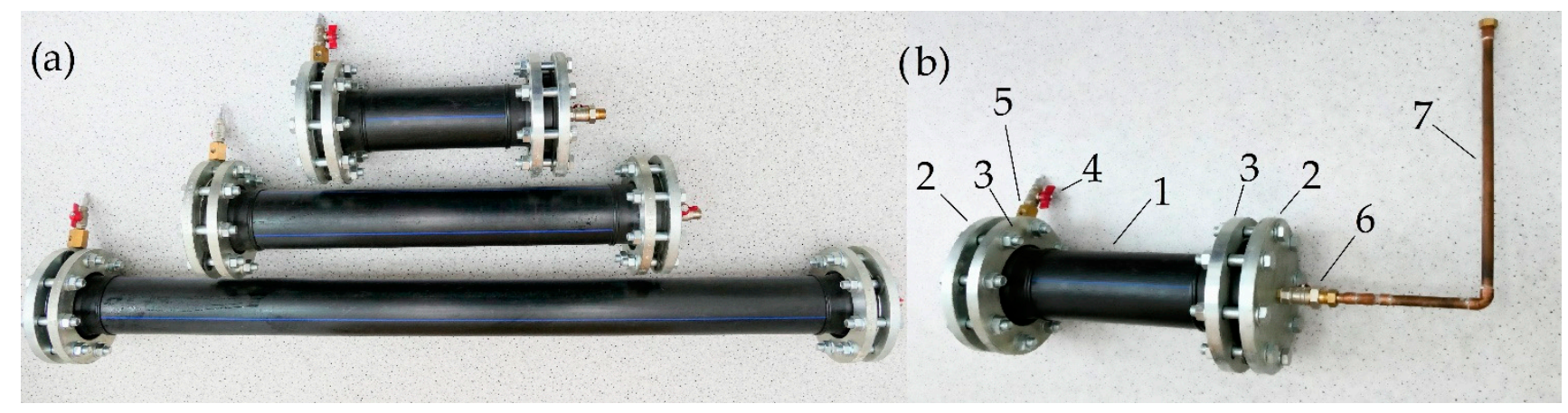

Figure 3. Additional pipes used in experimental study. (a) Additional pipes no. 1,2 and 3, (b) Additional pipe no. 1: 1-HDPE pipe, 2-steel lids, 3-steel rings, 4-vent valve, 5-pressure sensor socket, 6-shut-off valve, 7connection pipe.

Each of the devices consisted of an HDPE pipe (labelled 1 in Figure $3 b$ ) and steel lids (labelled 2 in Figure 3b) connected to the pipe with steel rings (labelled 3 in Figure 3b), a vent valve (labelled 4 in Figure 3b), pressure sensor socket (labelled 5 in Figure 3b), shut-off valve (labelled 6 in Figure $3 b$ ) and connection pipe (labelled 7 in Figure $3 b$ ).

Water hammer runs were conducted in two variants: with and without AP installed. For each experimental variant, two types of water hammer were induced: rapid and slow manual valve closure. For each variant of the experiment, eight runs were carried out, which included three rapid water hammer and five slow water hammer events. Overall, 32 water hammer runs were conducted. In order to compare individual experimental results with each other, the measurements were carried out with care, to maintain a constant discharge during a steady flow of approximately $183 \mathrm{~m}^{3} / \mathrm{h}$, which corresponded to an initial velocity of $0.39 \mathrm{~m} / \mathrm{s}$.

The collected data enabled the creation of graphs of pressure oscillations and valve opening angles as a function of time. Their analysis was used to obtain the water hammer parameters: maximum pressure head, pressure wave velocity and time of valve closure. Examples of the measurement results for rapid and slow valve closures are presented in Figures 4 and 5 . 


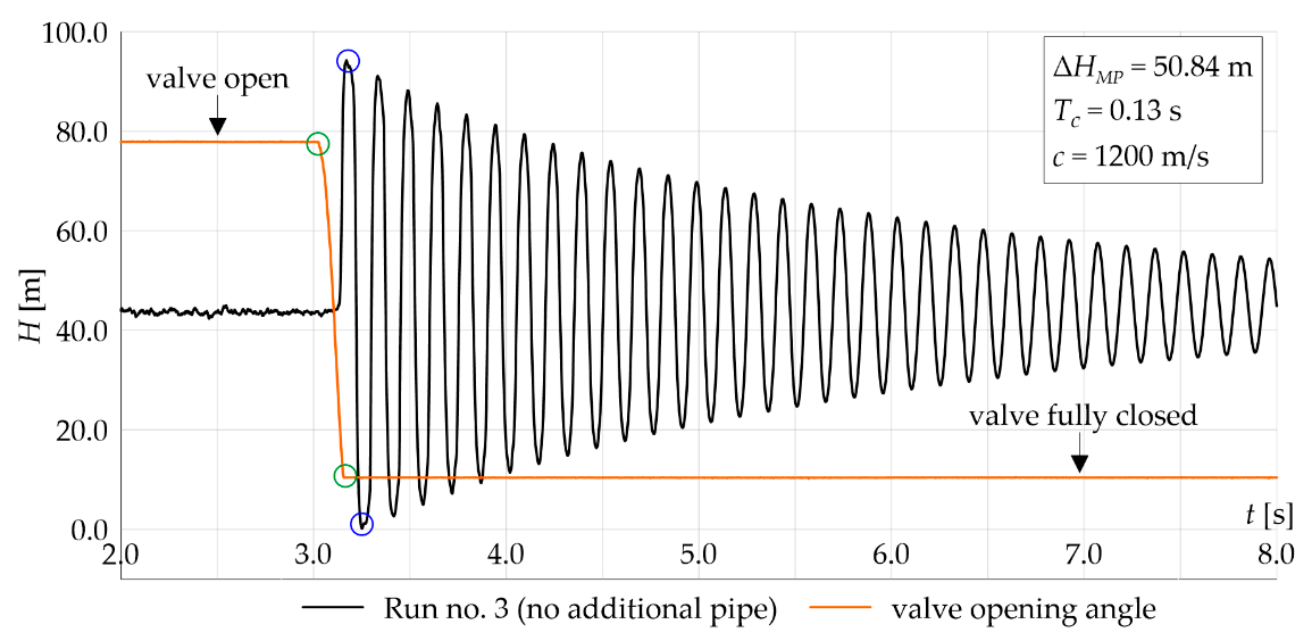

Figure 4. Pressure oscillations recorded during run no. 3 (data obtained with sensor $\mathrm{P}_{\mathrm{M}}$ ).

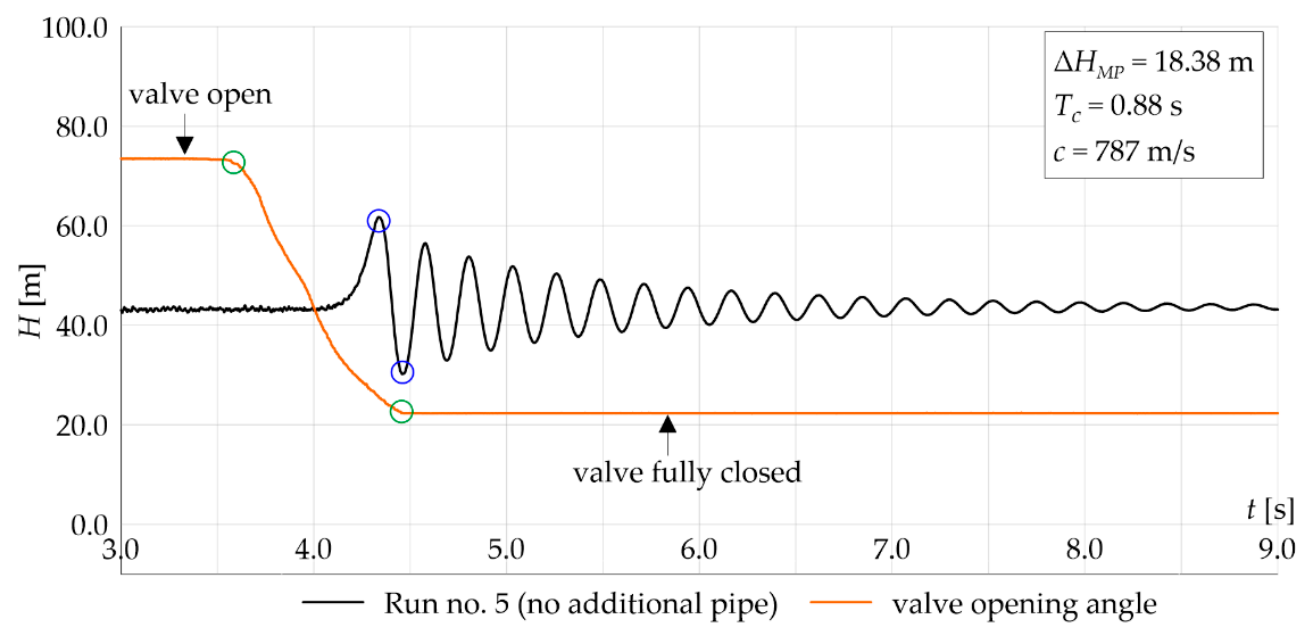

Figure 5. Pressure oscillations recorded during run no. 5 (data obtained with sensor $\mathrm{P}_{\mathrm{M}}$ ).

As shown in Figure 4, the maximum pressure increase in the MP without AP installed was equal to $50.84 \mathrm{~m}$. The orange plot in Figures 4 and 5 represents the valve opening angle and does not correspond to values of pressure head in the vertical axis. In order to determine the time of valve closure which initiated the water hammer phenomenon, the time difference between the start and the end of valve closing was read (marked with green circles in Figures 4 and 5). Experimentally obtained pressure oscillations are a harmonic function with a period equal to the pipeline period of the reflection time. To determine pressure wave speed, the time difference between minimum and maximum pressure was considered (marked with blue circles in Figures 4 and 5). The main characteristics of all experimental runs are reported in Table 2. 
Table 2. Data from experimental runs.

\begin{tabular}{|c|c|c|c|c|c|c|c|}
\hline Run & $\begin{array}{l}\text { Variant of } \\
\text { Experiment }\end{array}$ & $\begin{array}{l}\text { Type of Valve } \\
\text { Closure }\end{array}$ & $\begin{array}{c}v_{0} \\
{[\mathrm{~m} / \mathrm{s}]}\end{array}$ & $\begin{array}{l}T_{C} \\
{[\mathrm{~s}]}\end{array}$ & $\begin{array}{l}\Delta H_{M P} \\
{[\mathrm{MPa}]}\end{array}$ & $\begin{array}{l}\Delta H_{A P} \\
{[\mathrm{MPa}]}\end{array}$ & $\begin{array}{c}c \\
{[\mathrm{~m} / \mathrm{s}]}\end{array}$ \\
\hline 1 & no AP & rapid & 0.38 & 0.14 & 49.79 & - & 1143 \\
\hline 2 & no AP & rapid & 0.39 & 0.14 & 50.33 & - & 1171 \\
\hline 3 & no AP & rapid & 0.39 & 0.13 & 50.84 & - & 1200 \\
\hline 4 & no AP & slow & 0.40 & 0.77 & 24.68 & - & 828 \\
\hline 5 & no AP & slow & 0.39 & 0.88 & 18.38 & - & 787 \\
\hline 6 & no AP & slow & 0.41 & 1.53 & 15.89 & - & 727 \\
\hline 7 & no AP & slow & 0.39 & 2.99 & 10.29 & - & 701 \\
\hline 8 & no AP & slow & 0.40 & 4.87 & 4.85 & - & 238 \\
\hline 9 & AP no. 1 & rapid & 0.38 & 0.12 & 29.83 & 26.58 & 407 \\
\hline 10 & AP no. 1 & rapid & 0.38 & 0.14 & 29.29 & 26.16 & 407 \\
\hline 11 & AP no. 1 & rapid & 0.39 & 0.14 & 29.74 & 26.63 & 407 \\
\hline 12 & AP no. 1 & slow & 0.38 & 0.78 & 17.91 & 23.10 & 425 \\
\hline 13 & AP no. 1 & slow & 0.39 & 1.44 & 14.26 & 17.55 & 417 \\
\hline 14 & AP no. 1 & slow & 0.39 & 1.98 & 13.07 & 15.18 & 407 \\
\hline 15 & AP no. 1 & slow & 0.39 & 3.59 & 8.65 & 9.39 & 358 \\
\hline 16 & AP no. 1 & slow & 0.38 & 4.43 & 9.18 & 9.99 & 381 \\
\hline 17 & AP no. 2 & rapid & 0.39 & 0.13 & 27.14 & 24.04 & 393 \\
\hline 18 & AP no. 2 & rapid & 0.39 & 0.14 & 27.18 & 24.17 & 397 \\
\hline 19 & AP no. 2 & rapid & 0.39 & 0.14 & 26.80 & 23.44 & 393 \\
\hline 20 & AP no. 2 & slow & 0.39 & 1.03 & 17.43 & 21.71 & 410 \\
\hline 21 & AP no. 2 & slow & 0.39 & 1.24 & 16.76 & 21.35 & 403 \\
\hline 22 & AP no. 2 & slow & 0.39 & 1.48 & 14.78 & 19.17 & 400 \\
\hline 23 & AP no. 2 & slow & 0.38 & 2.35 & 13.84 & 16.74 & 414 \\
\hline 24 & AP no. 2 & slow & 0.38 & 3.24 & 7.15 & 7.45 & 333 \\
\hline 25 & AP no. 3 & rapid & 0.38 & 0.15 & 31.22 & 31.66 & 480 \\
\hline 26 & AP no. 3 & rapid & 0.39 & 0.15 & 30.30 & 31.51 & 480 \\
\hline 27 & AP no. 3 & rapid & 0.39 & 0.15 & 30.87 & 31.11 & 480 \\
\hline 28 & AP no. 3 & slow & 0.38 & 1.46 & 17.74 & 21.99 & 533 \\
\hline 29 & AP no. 3 & slow & 0.38 & 1.91 & 13.20 & 14.71 & 505 \\
\hline 30 & AP no. 3 & slow & 0.38 & 2.46 & 8.73 & 9.10 & 421 \\
\hline 31 & AP no. 3 & slow & 0.39 & 3.46 & 6.32 & 6.32 & 378 \\
\hline 32 & AP no. 3 & slow & 0.39 & 3.96 & 6.11 & 6.13 & 385 \\
\hline
\end{tabular}

$v_{0}$ is the initial flow velocity, $T_{C}$ is the valve closing time, $\Delta H_{M P}$ is the maximum pressure increase in the main pipeline (obtained with sensor $\mathrm{P}_{\mathrm{M}}$ ) and $\Delta H_{A P}$ is the maximum pressure increase in the additional pipe (obtained with sensor $\mathrm{P}_{\mathrm{A}}$ ).

Table 1 demonstrates that, for the runs with rapid valve manoeuvring, it was closed between $0.12 \mathrm{~s}$ and $0.15 \mathrm{~s}$. For experiments with $\mathrm{AP}$, the pressure wave velocity did not exceed $500 \mathrm{~m} / \mathrm{s}$, and the time period of the pressure wave reflection time was longer than $2 L / c=2 \cdot 48 / 500=0.192 \mathrm{~s}$, so the valve was closed faster than the reflected pressure wave travel time. For cases without AP, the highest recorded pressure wave velocity was $1200 \mathrm{~m} / \mathrm{s}$ and period of the wave reflection time was $0.080 \mathrm{~s}$, which is shorter than the valve closing time. However, the observed maximum pressure increases are consistent with those calculated using the Joukowsky formula. Moreover, thorough analysis of the observed valve closing angle, along with pressure oscillations as a function of time (Figure 4) shows that the maximum pressure increase occurs before the valve is fully closed. For this reason, all the water hammer runs with rapid valve manoeuvring were considered as being induced with instantaneous valve closures. These results are consistent with observations from the similar high-frequency pipeline system presented in [33].

\section{Analysis of Experimental Data}

In order to compare the performance of a particular AP on the maximum pressure increase in the MP at the downstream valve section, for each of the experiments, values of $\Delta H_{M P}$ are presented as a function of valve closing time in Figure 6. 


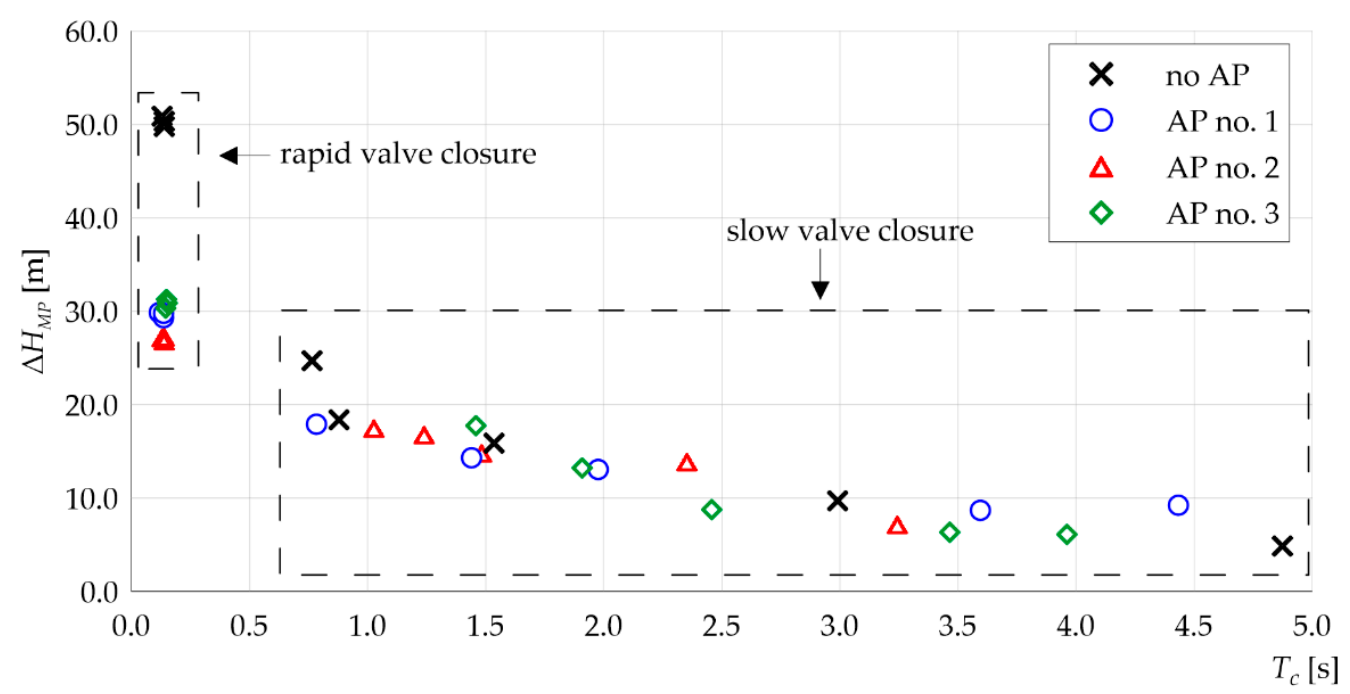

Figure 6. Values of maximum pressure increase in main pipeline for each experiment as a function of valve time closure (data obtained with sensor $\mathrm{P}_{\mathrm{M}}$ ).

Figure 5 clearly shows that installing the AP has a significant damping effect on the initial stage of pressure oscillations (first pressure peak) during rapid valve closure. In the pipeline without the device, for the shortest valve closing times, the maximum pressure increases exceed $50 \mathrm{~m}$. The unsteady flow oscillations observed during the tests with the $\mathrm{AP}$ are approximately $30 \mathrm{~m}$. The lowest pressure increase was recorded for AP no. $2\left(\Delta H_{M P}\right.$ is between $26.80 \mathrm{~m}$ and $27.18 \mathrm{~m})$ and the highest for AP no. $3\left(\Delta H_{M P}\right.$ is between $30.30 \mathrm{~m}$ and $31.22 \mathrm{~m}$ ). The lowest attenuation of pressure wave induced by instantaneous valve closure was obtained for AP no. 3 and was equal to $50.84 \mathrm{~m}-31.22 \mathrm{~m}=19.62 \mathrm{~m}$. The best performance was observed during experiments with device no. 2 and the attenuation was equal to $50.84 \mathrm{~m}-26.80 \mathrm{~m}=24.04 \mathrm{~m}$. In other words, experiments results reveal that the damping rates of the additional pipes were between $38 \%$ and $47 \%$. Interestingly, no relationship between the volume of $\mathrm{AP}$ and the damping properties was observed. This is likely due to the properties of the copper pipe which connects AP to the MP. The small diameter of the connecting section probably limits the AP's capacity to attenuate pressure waves. It should be noted that in experiments with a sudden valve closure, consistent values of maximum pressure increase were obtained for each of the APs, which proves the reliability of the results.

As the valve closing time lengthens, the influence of the AP on the maximum pressure oscillations is reduced. The results of slow water hammer experiments showed that the maximum pressure increases in the MP (with and without the device) are practically the same. By comparing the maximum pressure increases obtained during different runs for valve closing times of approximately $1.5 \mathrm{~s}(15.89 \mathrm{~m}$ for run without AP, $14.26 \mathrm{~m}$ for AP no. 1, $14.78 \mathrm{~m}$ for AP no.2 and $17.74 \mathrm{~m}$ for AP no. 3), it is apparent that differences between these cases do not exceed $3.5 \mathrm{~m}$. Thus, the additional HDPE pipe does not provide notable protection against hydraulic transients induced by a slow valve closure in terms of reducing the first pressure peak. To illustrate the influence of the AP on the unsteady flow oscillations at the downstream end of the MP during a rapid water hammer event, data with and without the AP were compared (Figure 7). 


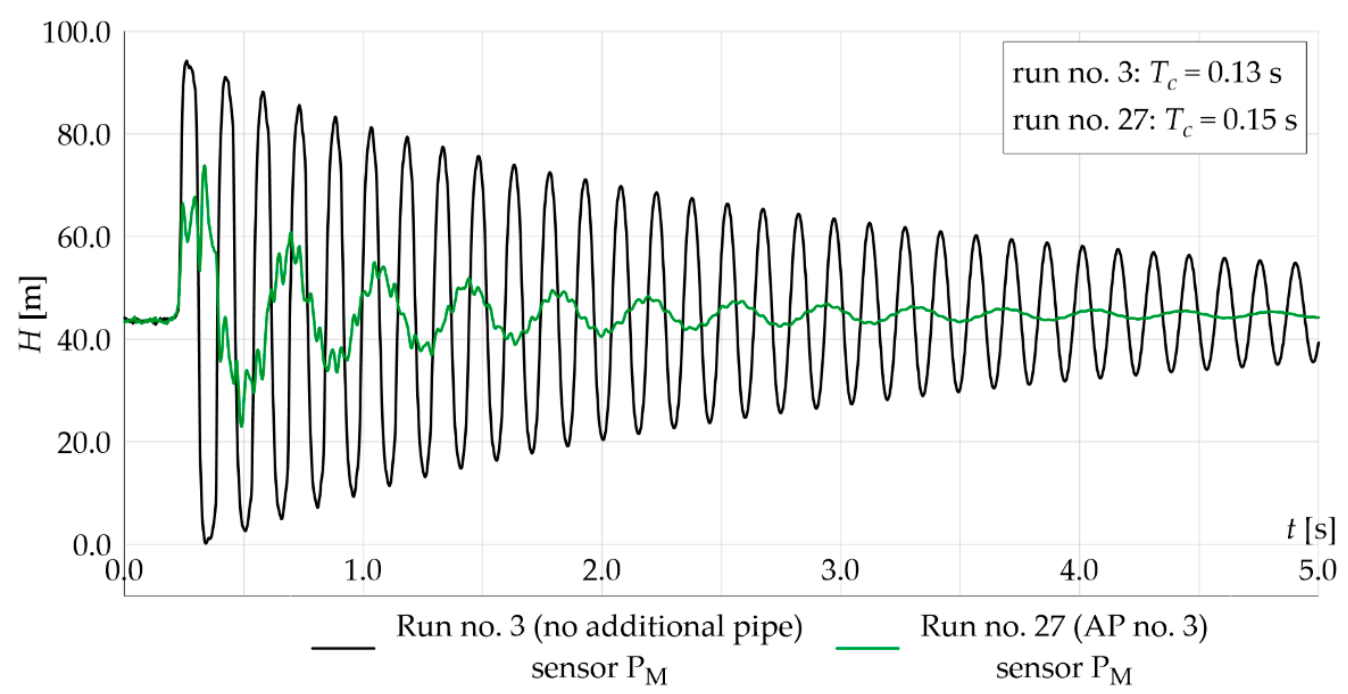

Figure 7. Pressure oscillations recorded during runs no. 3 and no. 27.

Figure 7 shows that a highly deformable AP provides significant pressure surge damping during a rapid water hammer event. Much more severe transients were induced in the main pipeline without the device, both in terms of maximum pressure increase and the duration of unsteady flow oscillations. The observed maximum surge damping rate in the main pipeline system with an additional pipe is $40 \%$. There were strong disturbances in the pressure fluctuations in the MP with AP installed, which are typical of pipeline systems with sudden cross section changes [34]. Figures 8 and 9 illustrate experimental pressure oscillations induced by slow valve closures.

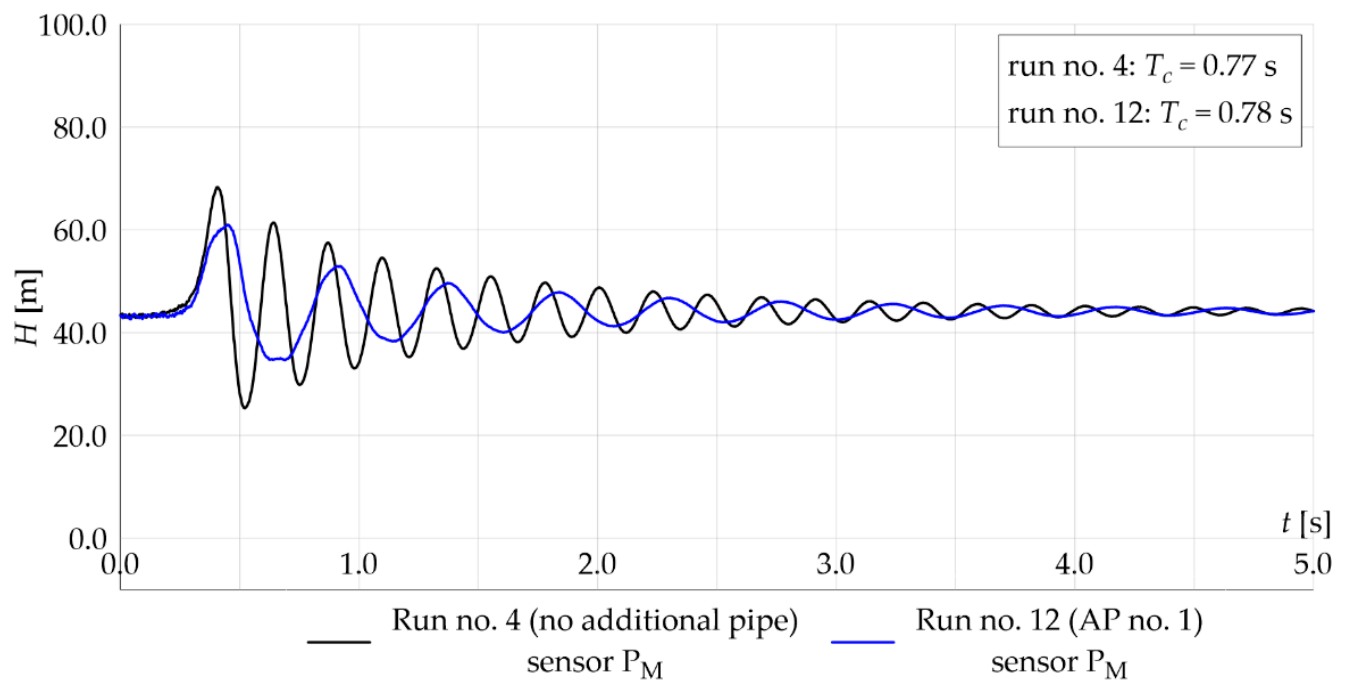

Figure 8. Pressure oscillations recorded during runs no. 4 and no. 12 . 


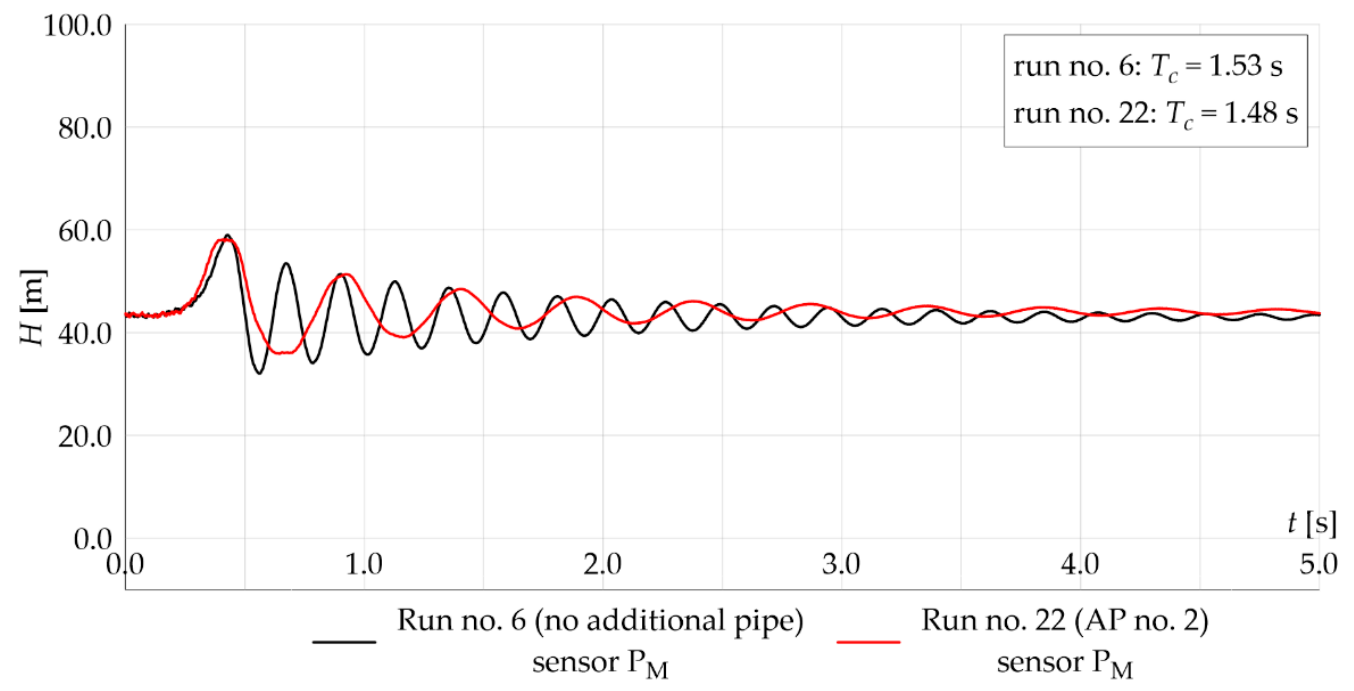

Figure 9. Pressure oscillations recorded during runs no. 6 and no. 22.

As can be seen in Figures 8 and 9, in the case of slow rapid water hammer events, the AP has a much smaller impact on the maximum pressure increase. For valve closing times between $0.77 \mathrm{~s}$ and $0.78 \mathrm{~s}$ (Figure 8), the maximum pressure increase in the main pipeline with the device $\left(\Delta H_{M P}=17.91 \mathrm{~m}\right)$ is $73 \%$ of the maximum pressure increase in the pipeline without the device $\left(\Delta H_{M P}=24.68 \mathrm{~m}\right)$. Increasing the valve closure time to approximately $1.5 \mathrm{~s}$ (Figure 8) causes the maximum pressure increase to be practically the same in the MP, with and without the device. However, it is apparent from Figure 9 that the AP reduces the duration of the phenomenon, as the pressure wave is dissipated and time dispersed. Based on Figures 8 and 9 and Table 2, it can be seen that installing the additional pipe spreads out the period of pressure oscillations. In the mentioned cases, the reduction in the observed pressure wave velocity is $51 \%(828 \mathrm{~m} / \mathrm{s}$ in run 4 and $425 \mathrm{~m} / \mathrm{s}$ in run 12$)$ and $55 \%(727 \mathrm{~m} / \mathrm{s}$ in run 6 and $400 \mathrm{~m} / \mathrm{s}$ in run 22). This is due to viscoelastic mechanical behaviour of the additional pipe and its response to pressure load during transients. In addition, in the case of slow water hammer runs, pressure disturbances do not come from the connection pipe.

So far, the data obtained from the pressure sensor installed in the main pipeline (sensor $\mathrm{P}_{\mathrm{M}}$ ) were analysed. Turning now to observed pressure changes in the AP, it should be noted that maximum pressure increases in the MP are not the same as in the AP (Table 2). In order to compare these values, ratios of $\Delta H_{M P} / \Delta H_{A P}$ are presented in Figure 10 as a function of valve closing time.

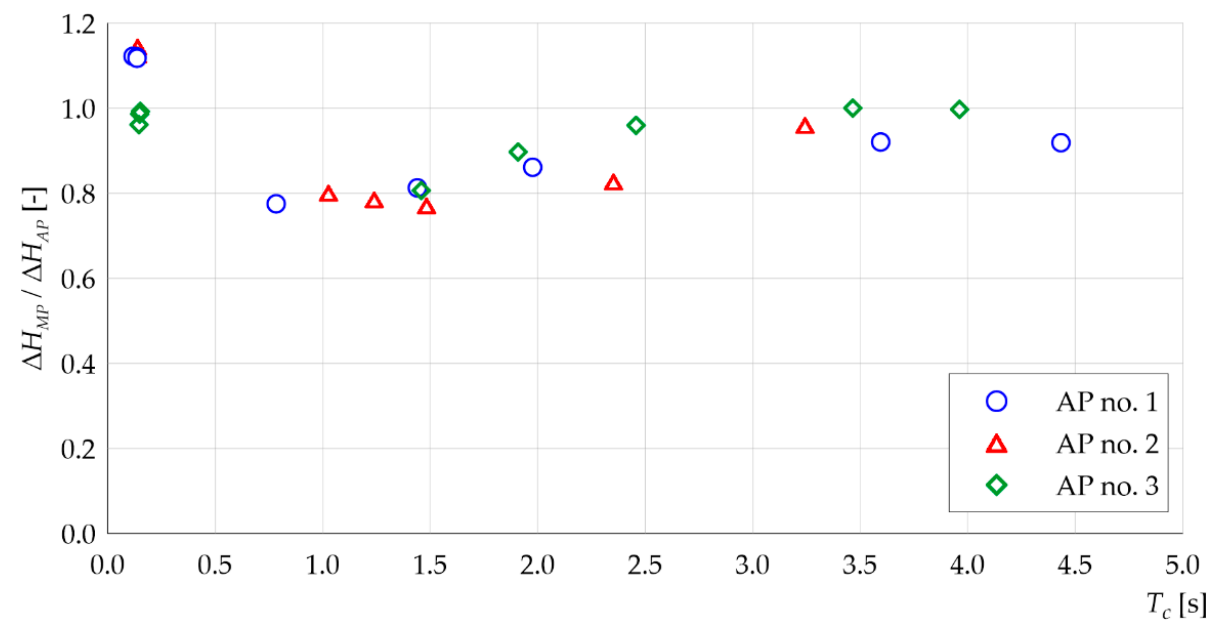

Figure 10. Values of $\Delta H_{M P} / \Delta H_{A P}$ ratios as a function valve closing time (data obtained with sensors $\mathrm{P}_{\mathrm{M}}$ and $\left.\mathrm{P}_{\mathrm{A}}\right)$. 
As illustrated in Figure 10, for cases with rapid valve closure, the maximum pressure increase in the MP is actually higher than the pressure increase in the AP. For all cases, extending the valve closing time to approximately $0.7 \mathrm{~s}$ to $1.5 \mathrm{~s}$ causes the observed maximum pressure increase in MP to be lower than in AP. Interestingly, it can be noted that, as the valve closing time further increases, the values of the $\Delta H_{M P} / \Delta H_{A P}$ ratios tend to 1. A possible explanation for this effect is presented on the examples of individual experimental results. The largest differences between pressure increases in the MP and AP were observed for AP no. 2. The comparison of pressure oscillations observed in the MP and the AP for a rapid valve closure are presented in Figure 11.

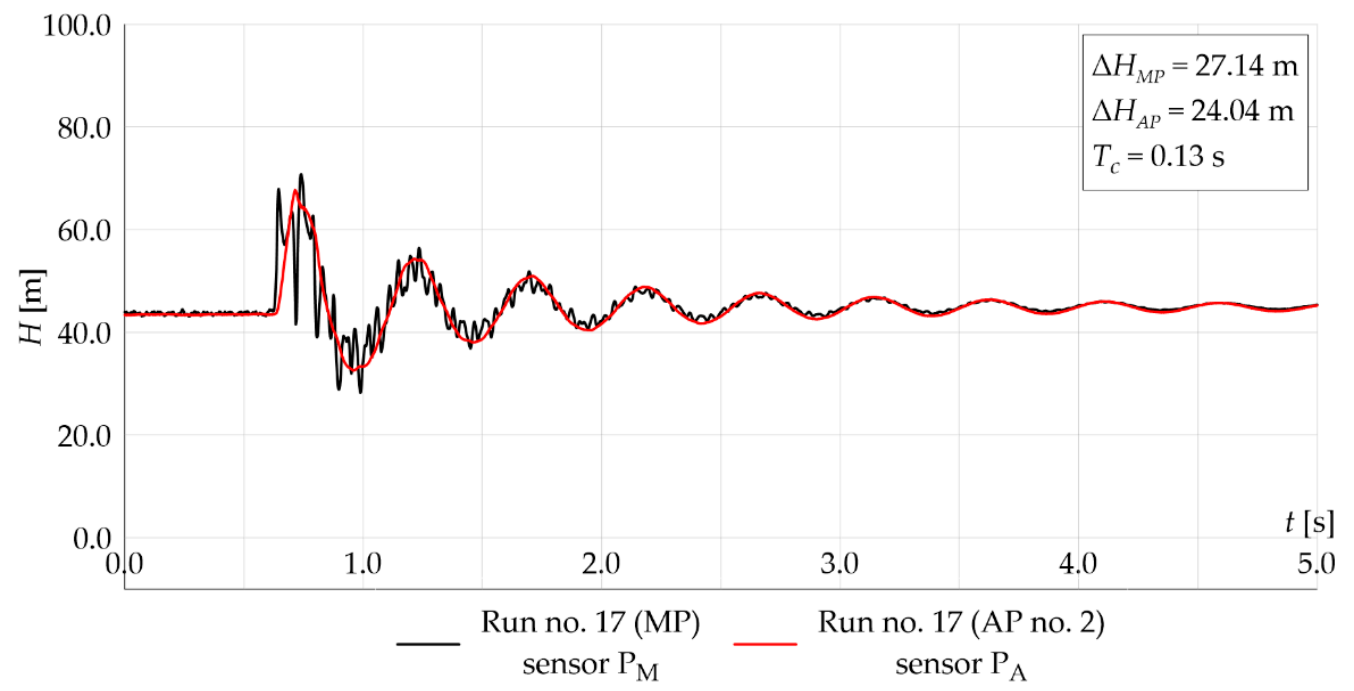

Figure 11. Pressure oscillations observed during run no. 17.

The unsteady flow oscillations in MP and AP, observed during the water hammer run induced by slow valve closure, are presented in Figure 12.

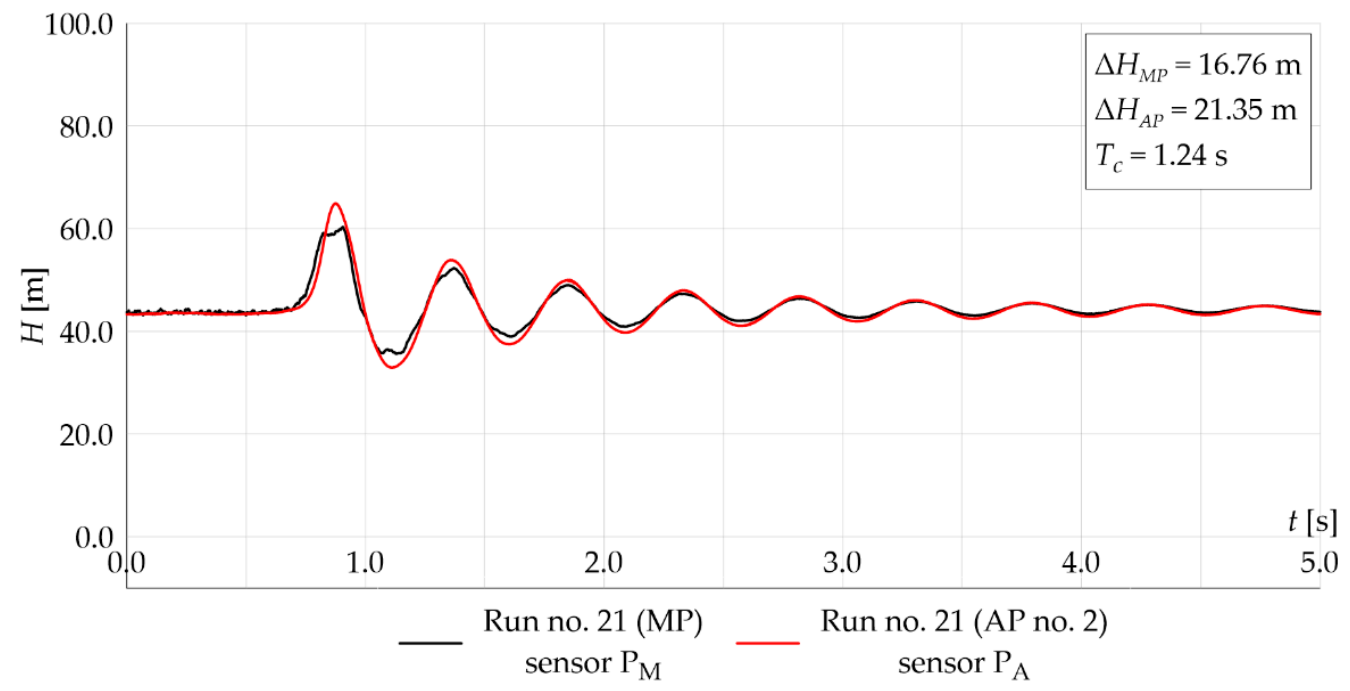

Figure 12. Pressure oscillations observed during run no. 21.

As can be seen in Figure 11, the maximum pressure increase in the MP is higher than in the AP due to the pressure disturbances. Transient pressure waves are partially reflected by any change in the physical structure of the pipe [35]. During rapid water hammer events, the AP connected to the MP acts as a branch with a different diameter, in which the transmission and reflection of pressure waves occurs [36,37]. This effect is potentially disadvantageous for damping pressure surges. For example, it is known that an insufficient connector discharge capacity of the surge tank may intensify water hammer 
elsewhere in the pipeline [14]. Figure 12 shows that during less severe hydraulic transients, the maximum pressure increase in the MP is lower than in the AP. This is likely due to the fact that the viscoelastic effect affects low frequencies more severely [38]. As the pressure wave attenuates, local losses (due to diameter change in the connection pipe) cause energy dissipation and the local maximum pressure recorded by the sensor in the AP (Figure 3) is lower than in the MP. Figures 11 and 12 show that, as the pressure wave dampens, the differences between the unsteady flow pressure oscillations in MP and AP disappear, hence the values of $\Delta H_{M P} / \Delta H_{A P}$ ratios presented in Figure 10 tend to 1.

\section{Numerical Solution and Model Validation}

The aim of the conducted numerical analysis was to simulate unsteady flow oscillations in the MP (with the AP installed), induced by instantaneous valve closure. The numerical analysis of water hammer is obtained by approximating the solutions of the continuity and momentum equations. Several numerical methods are available to solve transient flow equations. In particular, method of characteristics (MOC) schemes are wellknown by both researchers and practitioners [39]. In this paper, a popular fixed grid MOC approach was used to simulate water hammer in the pipeline with the AP installed. The presence of the device in the pipeline system was included in the form of a downstream boundary condition. An illustration of the discretisation scheme is shown in Figure 13.
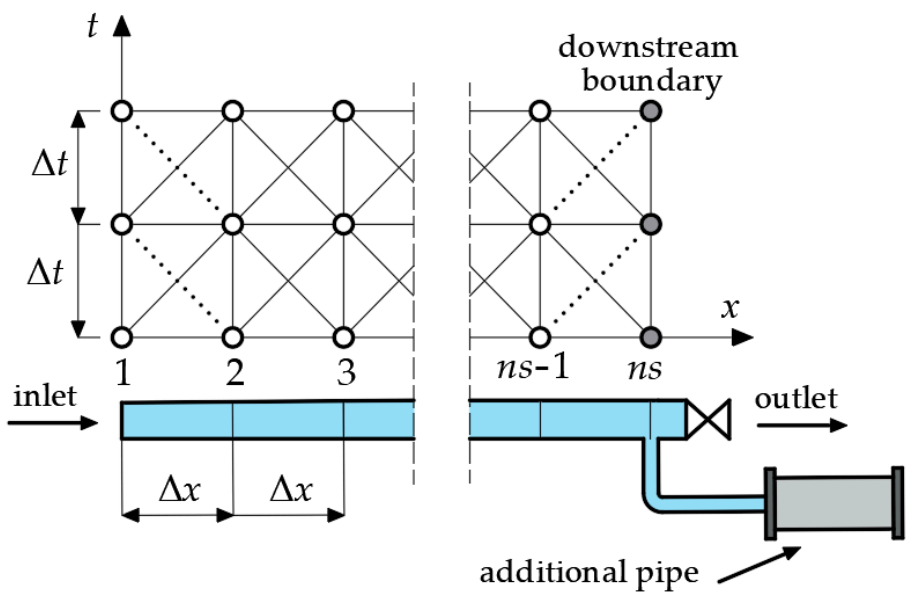

Figure 13. Characteristic grid used in numerical calculations.

As can be seen in Figure 13, the AP is located downstream, i.e., in the junction ns. Therefore, the characteristic equation is positive and yields:

$$
Q_{n s}^{t+\Delta t}-Q_{n s-1}^{t}+\frac{g A}{c}\left(H_{n s}^{t+\Delta t}-H_{n s-1}^{t}\right)+\frac{f\left|Q_{n s-1}^{t}\right| Q_{n s-1}^{t}}{2 D A} \Delta t=0
$$

By substituting differential ratios in Equation (10) with finite differences, one obtains:

$$
Q_{n s}^{t+\Delta t}=2 \frac{\partial \varepsilon}{\partial t} W_{A P}+H_{n s}^{t+\Delta t} \frac{g W_{A P}}{c_{A P}^{2} \Delta t}-H_{n s}^{t} \frac{g W_{A P}}{c_{A P}^{2} \Delta t}
$$

Combining Equations (11) and (12) yields:

$$
H_{n s}^{t+\Delta t}=\frac{2 \frac{\partial \varepsilon}{\partial t} W_{A P}-H_{n s}^{t} \frac{g W_{A P}}{c_{A P}^{2} \Delta t}-Q_{n s-1}^{t}-\frac{g A}{c} H_{n s-1}^{t}+\frac{f\left|Q_{n s-1}^{t}\right| Q_{n s-1}^{t}}{2 D A}}{-\frac{g A}{c}-\frac{g W_{A P}}{c_{A P}^{2} \Delta t}}
$$


The retarded strain in Equation (8) is computed as a sum of each Kelvin-Voigt element $[30,40]$ :

$$
\frac{\partial \varepsilon_{r}^{t-\Delta t}}{\partial t}=\sum_{i=1}^{n} \frac{\partial \varepsilon_{r}^{t-\Delta t}}{\partial t}=\sum_{k=1}^{n}\left[\frac{\alpha D_{A P}}{2 S_{A P}} \frac{J_{k}}{\tau_{k}} \rho g\left(H_{n s}^{t-\Delta t}-H_{n s}^{t=0}\right)-\frac{\varepsilon_{i}^{t-\Delta t}}{\tau_{i}}\right]
$$

The numerical approximation of each retarded strain in each node is equal to:

$$
\varepsilon_{r i}^{t-\Delta t}=J_{i} F^{t-\Delta t}-J_{i} e^{-\frac{\Delta t}{\tau_{i}}} F^{t-2 \Delta t}-J_{i} \tau_{i}\left(1-e^{-\frac{\Delta t}{\tau_{i}}}\right) \frac{F^{t-\Delta t}-F^{t-2 \Delta t}}{\Delta t}+e^{-\frac{\Delta t}{\tau_{i}}} \varepsilon_{r i}^{t-2 \Delta t}
$$

With the function $F$ at time $t-\Delta t$ described as:

$$
F^{t-\Delta t}=\frac{\alpha D_{A P}}{2 S_{A P}} \frac{J_{i}}{\tau_{i}} \rho g\left(H_{n s}^{t-\Delta t}-H_{n s}^{t=0}\right)
$$

After calculating the pressure at the downstream end from Equation (13), along with Equations (14)-(16), discharge can be calculated from:

$$
Q_{n s}^{t+\Delta t}=Q_{n s}^{t}+\frac{g A}{c}\left(H_{n s-1}^{t}-H_{n s}^{t+\Delta t}\right)
$$

As mentioned previously, the presented numerical model holds for water hammer events induced by rapid valve closure at the downstream end of the pipeline. In order to validate the approach of a lumped parameter in the context of the AP connected to the MP via a conduit with a small diameter, computed results were compared with the experimental data recorded during run no. 17 (Table 2). Calculations were carried out with the space step of $\Delta x=1 \mathrm{~m}$ and the time step of $\Delta t=0.00082 \mathrm{~s}$ which enabled the Courant number to be obtained as close to unity as possible $(\mathrm{Ca}=0.99)$, eliminating numerical dissipation and dispersion. The dimensions of the main pipeline system used in the experimental tests and parameters of AP no. 2 are listed in Table 1 and these were used as an input. The pressure wave velocity was determined on the basis of measurements in the pipeline without the device $(c=1200 \mathrm{~m} / \mathrm{s})$. The steady-state friction factor was calculated for an assumed pipe roughness of $0.08 \mathrm{~mm}$ using the Colebrook-White formula. For simplicity, calibration of the numerical model was performed using only one Kelvin-Voigt element. The values of retardation time $(\tau=0.0447 \mathrm{~s})$, creep compliance $\left(J=3.33 \times 10^{-9} \mathrm{~Pa}^{-1}\right)$ and pressure wave velocity in the AP $\left(c_{d}=190 \mathrm{~m} / \mathrm{s}\right)$ were estimated by a trial and error method, to minimise the mean squared error between the calculated and experimental data. Figure 14 illustrates the comparison between calculated and observed $H(t)$ functions.

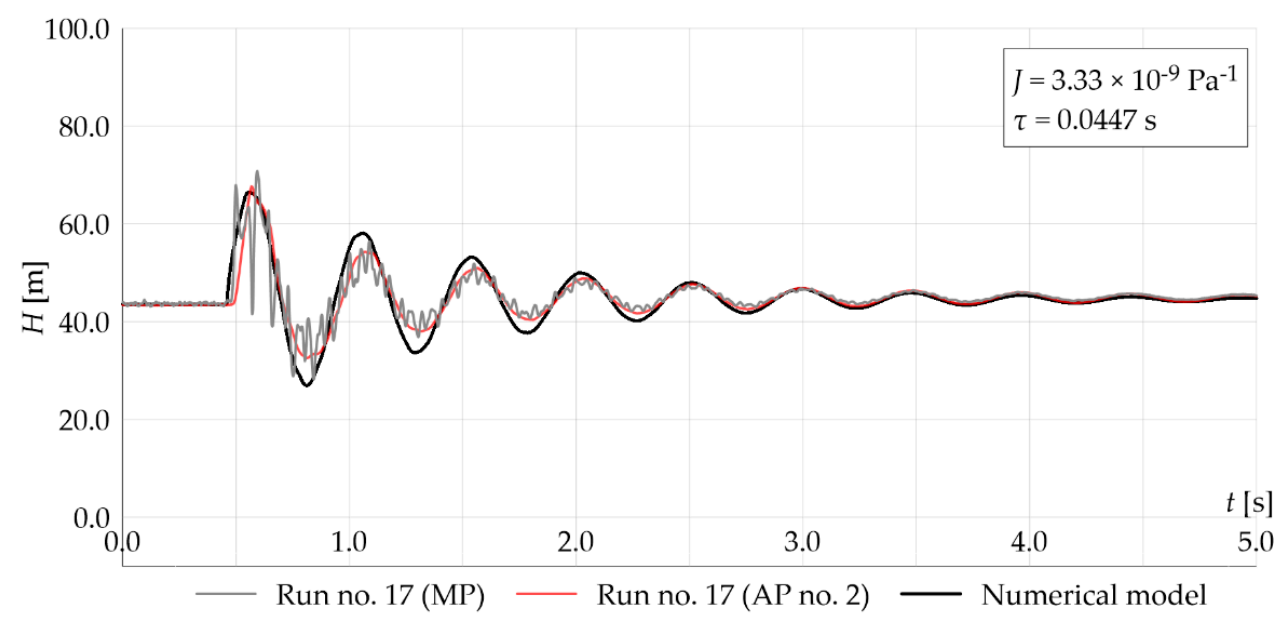

Figure 14. Comparison between calculated and observed pressure oscillations. 
As can be seen in Figure 14, the computation results agree well with the experimental data, in terms of pressure oscillation periods. Differences in calculated and observed maximum pressure increase in the main pipeline are due to the pressure wave reflections and transmissions discussed previously. Calculation results show that this model can be useful in practice, as it allows estimation of the pressure increase resulting from rapid valve closure. The main advantage of this approach is that it is easy to implement in the form of a boundary condition and a relatively small number of parameters characterising the device. Use of the viscoelastic model allows the reproduction of dissipation and dispersion of the pressure wave. However, the presented numerical model has obvious limitations. It does not take into account the method of connecting the AP into the MP and, thus, it does not reproduce pressure disturbances in the MP that were observed during experimental tests. Another weakness is that the choice of values of creep compliance, retardation time and the number of Kelvin-Voigt elements applied in simulations, determines the obtained results in a significant way. For the correct description of the viscoelastic response of the pipeline, it is necessary to determine the coefficients of the model of the flexible material used [41]. This is a well-known problem in modelling the viscoelastic response of pipe-wall material in pressurised pipeline systems [42,43]. Values of viscoelastic parameters, along with values of pressure wave velocities (both in the MP and the AP), are very difficult to assess and should be estimated on the basis of calibration procedures.

\section{Conclusions}

In this paper, the reduction in water hammer pressure waves in a steel pipeline using additional HDPE pipe was analysed. A previous study on this topic investigated additional polymeric pipes connected to the hydraulic system with a short joint section of the same diameter as the main pipeline. In the current research, a different method of including an additional pipe was considered which involved connecting it with a pipe of a smaller diameter than the main pipeline. This way of including an additional pipe in the hydraulic system makes it much more convenient to implement the device in the existing systems. In general, the following conclusions can be made:

1. The experimental tests showed that the additional polymeric pipe can be successfully used to attenuate a pressure surge during a water hammer event induced by rapid valve closure. Comparing the pressure oscillations in the pipeline with and without the device, it is apparent that an additional pipe significantly reduces the maximum pressure increase and reduces the duration of the phenomenon.

2. As the valve closing time lengthens, the influence of the additional pipe on the maximum pressure increase is reduced. Results of experimental runs showed that, during less severe hydraulic transients, values of maximum pressure increase in the pipeline, with and without the device, are similar. Thus, additional HDPE pipe does not provide notable protection against hydraulic transients induced by slow valve closure in terms of reducing the first pressure peak.

3. In all analysed cases, both for rapid and slow valve closures, the presence of a polymeric additional pipe causes a reduction in pressure wave velocity and lengthens the period of pressure oscillations.

4. In this study, the performance of three devices with different volumes was experimentally analysed. The apparent lack of correlation between the volume of the additional polymeric pipe and its ability to attenuate pressure waves can be attributed to the small diameter of the connection pipe compared with the diameter of the device. This way of connecting additional pipes to the main pipeline, although justified by practical reasons, makes the device less effective. Further data collection is required to evaluate the influence of the connection pipe on the performance of the additional polymeric pipes.

5. In order to simulate the water hammer phenomenon, a numerical model in which an additional pipe is treated as a lumped parameter was used. Experimental data was used to calibrate the mechanical properties of the pipeline system. The calculation 
results showed that this approach allows the reasonable reproduction of unsteady flow oscillations registered during experiments, in terms of maximum pressure increase and pressure wave oscillation period.

Author Contributions: Conceptualisation, M.K. and A.K.; methodology, M.K., A.K. and A.M.; software, M.K., A.M. and K.U.; validation, M.K., M.S. and P.B.; formal analysis, M.K., K.U., A.M. and M.S.; investigation, M.K and K.U.; resources, M.K., A.K. and K.U.; writing-original draft preparation, M.K. and A.M.; writing-review and editing, A.K., K.U., P.B. and M.S.; visualisation, M.K.; supervision, M.K. and A.M.; project administration, M.K.; funding acquisition, M.K. All authors have read and agreed to the published version of the manuscript.

Funding: This work was supported by the Faculty of Building Services, Hydro and Environmental Engineering, Warsaw University of Technology (Grant no. 504/04608).

Institutional Review Board Statement: Not applicable.

Informed Consent Statement: Not applicable.

Data Availability Statement: The code generated during the study and experimental data are available from the corresponding author by request.

Conflicts of Interest: The authors declare no conflict of interest.

\section{Nomenclature}

A cross sectional area of the main pipeline $\left(\mathrm{m}^{2}\right)$

$c \quad$ pressure wave velocity in the main pipeline $(\mathrm{m} / \mathrm{s})$

$c_{A P} \quad$ pressure wave velocity in the additional pipe $(\mathrm{m} / \mathrm{s})$

$D \quad$ main pipeline internal diameter $(\mathrm{m})$

$D_{A P} \quad$ additional pipe internal diameter $(\mathrm{m})$

$D_{A P 0} \quad$ inner diameter of the additional pipe at time $\mathrm{t}=0$

$f \quad$ friction factor (-)

$g \quad$ gravity acceleration $\left(\mathrm{m} / \mathrm{s}^{2}\right)$

$i \quad$ number of a single Kelvin-Voigt element (-)

$H \quad$ piezometric head (m)

$J(t) \quad$ creep compliance at time $t\left(\mathrm{~Pa}^{-1}\right)$

$J\left(t^{\prime}\right) \quad$ creep compliance at time $t^{\prime}\left(\mathrm{Pa}^{-1}\right)$

$L_{A P} \quad$ length of the additional pipe (m)

$n \quad$ total number of Kelvin-Voigt elements (-)

$Q \quad$ volumetric flow rate $\left(\mathrm{m}^{3} / \mathrm{s}\right)$

$p_{0} \quad$ initial pressure $(\mathrm{Pa})$

$p(t) \quad$ pressure at time $t(\mathrm{~Pa})$

$S_{A P} \quad$ additional pipe wall thickness (m)

$T_{C} \quad$ valve closing time (s)

$\mathrm{t} \quad$ time (s)

$v_{0} \quad$ initial average flow velocity $(\mathrm{m} / \mathrm{s})$

$v_{\mathrm{i}, \mathrm{L}} \quad$ velocity on the left hand side of the connection node $(\mathrm{m} / \mathrm{s})$

$v_{i, R} \quad$ velocity on the right hand side of the connection node $(\mathrm{m} / \mathrm{s})$

$W_{A P} \quad$ volume of the additional pipe $\left(\mathrm{m}^{3}\right)$

$W_{M P} \quad$ volume of the main pipeline $\left(\mathrm{m}^{3}\right)$

$x \quad$ space coordinate $(\mathrm{m})$

$\Delta H_{A P} \quad$ maximum pressure increase in the additional pipe (Pa)

$\Delta H_{M P} \quad$ maximum pressure increase in the main pipeline (Pa)

$\Delta t \quad$ time step (s)

$\Delta x \quad$ spatial step $(\mathrm{m})$ 


$\begin{array}{ll}\varepsilon & \text { unit instantaneous strain (-) } \\ \varepsilon_{0} & \text { instantaneous (elastic) strain (-) } \\ \varepsilon_{\mathrm{r}} & \text { retarded strain (-) } \\ \sigma & \text { stress (Pa) } \\ \tau_{\mathrm{i}} & \text { the retardation time of } i \text {-th Kelvin-Voigt element (s) } \\ \text { Acronyms } & \\ \text { AP } & \text { additional pipe } \\ \text { DAQ } & \text { data acquisition system } \\ \text { MOC } & \text { method of characteristics } \\ \text { HDPE } & \text { high-density polyethylene } \\ \text { MP } & \text { main pipeline }\end{array}$

\section{References}

1. Bergant, A.; Simpson, A.R.; Tijsseling, A.S. Water hammer with column separation: A historical review. J. Fluids Struct. 2006, 22, 135-171. [CrossRef]

2. Ramos, H.; Covas, D.; Borga, A.; Loureiro, D. Surge damping analysis in pipe systems: Modelling and experiments. J. Hydraul. Res. 2004, 42, 413-425. [CrossRef]

3. Bazargan-Lari, M.R.; Kerachian, R.; Afshar, H.; Bashi-Azghadi, S.N. Developing an optimal valve closing rule curve for real-time pressure control in pipes. J. Mech. Sci. Technol. 2013, 27, 215-225. [CrossRef]

4. Wan, W.; Li, F. Sensitivity Analysis of Operational Time Differences for a Pump-Valve System on a Water Hammer Response. J. Press. Vessel. Technol. 2016, 138, 011303. [CrossRef]

5. Yu, X.; Zhang, J.; Miao, D. Innovative Closure Law for Pump-Turbines and Field Test Verification. J. Hydraul. Eng. 2015, 141, 05014010. [CrossRef]

6. Zhou, J.; Xu, Y.; Zheng, Y.; Zhang, Y. Optimization of Guide Vane Closing Schemes of Pumped Storage Hydro Unit Using an Enhanced Multi-Objective Gravitational Search Algorithm. Energies 2017, 10, 911. [CrossRef]

7. Pérez-Sánchez, M.; López-Jiménez, P.; Ramos, H. PATs Operating in Water Networks under Unsteady Flow Conditions: Control Valve Manoeuvre and Overspeed Effect. Water 2018, 10, 529. [CrossRef]

8. Subani, N.; Amin, N. Analysis of Water Hammer with Different Closing Valve Laws on Transient Flow of Hydrogen-Natural Gas Mixture. Abstr. Appl. Anal. 2015, 2015, 510675. [CrossRef]

9. Boulos, P.F.; Karney, B.W.; Wood, D.J.; Lingireddy, S. Hydraulic Transient Guidelines for Protecting Water Distribution Systems. J. Am. Water Work. Assoc. 2005, 97, 111-124. [CrossRef]

10. Chaudhry, M.H. Applied Hydraulic Transients, 3rd ed.; Springer: New York, NY, USA, 2014; ISBN 978-1-4614-8538-4.

11. Stephenson, D. Simple Guide for Design of Air Vessels for Water Hammer Protection of Pumping Lines. J. Hydraul. Eng. 2002, 128, 792-797. [CrossRef]

12. Kim, S.-G.; Lee, K.-B.; Kim, K.-Y. Water hammer in the pump-rising pipeline system with an air chamber. J. Hydrodyn. 2014, 26, 960-964. [CrossRef]

13. Wan, W.; Zhang, B.; Chen, X.; Lian, J. Water Hammer Control Analysis of an Intelligent Surge Tank with Spring Self-Adaptive Auxiliary Control System. Energies 2019, 12, 2527. [CrossRef]

14. Wan, W.; Zhang, B. Investigation of Water Hammer Protection in Water Supply Pipeline Systems Using an Intelligent SelfControlled Surge Tank. Energies 2018, 11, 1450. [CrossRef]

15. Riasi, A.; Nourbakhsh, A. Influence of Surge Tank and Relief Valve on Transient Flow Behaviour in Hydropower Stations. In Proceedings of the ASME-JSME-KSME 2011 Joint Fluids Engineering Conference, Hamamatsu, Japan, 24-29 July 2011; Symposia-Parts A, B, C, and D.; ASMEDC: Hamamatsu, Japan, 2011; Volume 1, pp. 1971-1977.

16. Vereide, K.; Svingen, B.; Nielsen, T.K.; Lia, L. The Effect of Surge Tank Throttling on Governor Stability, Power Control, and Hydraulic Transients in Hydropower Plants. IEEE Trans. Energy Convers. 2017, 32, 91-98. [CrossRef]

17. Balacco, G.; Apollonio, C.; Piccinni, A.F. Experimental analysis of air valve behaviour during hydraulic transients. J. Appl. Water Eng. Res. 2015, 3, 3-11. [CrossRef]

18. Zhang, K.Q.; Karney, B.W.; McPherson, D.L. Pressure-relief valve selection and transient pressure control. J. Am. Water Work. Assoc. 2008, 100, 62-69. [CrossRef]

19. Kim, H.; Kim, S. Optimization of pressure relief valve for pipeline system under transient induced cavitation condition. Urban Water J. 2019, 16, 718-726. [CrossRef]

20. Bettaieb, N.; Taieb, E.H. Assessment of Failure Modes Caused by Water Hammer and Investigation of Convenient Control Measures. J. Pipeline Syst. Eng. Pract. 2020, 11, 04020006. [CrossRef]

21. Mery, H.O.; Hassan, J.M.; EKaid, A.L. Water Hammer Mitigation by Air Vessel and Bypass Forward Configuration. IOP Conf. Ser. Mater. Sci. Eng. 2021, 1094, 012052. [CrossRef]

22. Wróbel, J.; Blaut, J. Influence of Pressure inside a Hydraulic Line on Its Natural Frequencies and Mode Shapes. In Advances in Hydraulic and Pneumatic Drives and Control 2020; Stryczek, J., Warzyńska, U., Eds.; Lecture Notes in Mechanical Engineering; Springer International Publishing: Cham, Switzerland, 2021; pp. 333-343, ISBN 978-3-030-59508-1. 
23. Kubrak, M.; Kodura, A. Water Hammer Phenomenon in Pipeline with Inserted Flexible Tube. J. Hydraul. Eng. 2020, $146,04019054$. [CrossRef]

24. Pezzinga, G.; Scandura, P. Unsteady Flow in Installations with Polymeric Additional Pipe. J. Hydraul. Eng. 1995, $121,802-811$. [CrossRef]

25. Pezzinga, G. Unsteady Flow in Hydraulic Networks with Polymeric Additional Pipe. J. Hydraul. Eng. 2002, 128, 238-244. [CrossRef]

26. Triki, A. Water-hammer control in pressurized-pipe flow using an in-line polymeric short-section. Acta Mech. 2016, 227, 777-793. [CrossRef]

27. Triki, A. Comparative assessment of the inline and branching design strategies based on the compound technique. J. Water Supply Res. Technol.-Aqua 2021, 70, 155-170. [CrossRef]

28. Triki, A. Water-Hammer Control in Pressurized-Pipe Flow Using a Branched Polymeric Penstock. J. Pipeline Syst. Eng. Pract. 2017, 8, 04017024. [CrossRef]

29. Triki, A.; Trabelsi, M. On the in-series and branching dual-technique-based water-hammer control strategy. Urban Water J. 2021, 18, 631-639. [CrossRef]

30. Covas, D.; Stoianov, I.; Mano, J.F.; Ramos, H.; Graham, N.; Maksimovic, C. The dynamic effect of pipe-wall viscoelasticity in hydraulic transients. Part II-model development, calibration and verification. J. Hydraul. Res. 2005, 43, 56-70. [CrossRef]

31. Keramat, A.; Tijsseling, A.S.; Hou, Q.; Ahmadi, A. Fluid-structure interaction with pipe-wall viscoelasticity during water hammer. J. Fluids Struct. 2012, 28, 434-455. [CrossRef]

32. Keramat, A.; Kolahi, A.G.; Ahmadi, A. Waterhammer modelling of viscoelastic pipes with a time-dependent Poisson's ratio. J. Fluids Struct. 2013, 43, 164-178. [CrossRef]

33. Kodura, A. An Analysis of the Impact of Valve Closure Time on the Course of Water Hammer. Arch. Hydro-Eng. Environ. Mech. 2016, 63, 35-45. [CrossRef]

34. Malesinska, A.; Kubrak, M.; Rogulski, M.; Puntorieri, P.; Fiamma, V.; Barbaro, G. Water Hammer Simulation in a Steel Pipeline System with a Sudden Cross-section Change. J. Fluids Eng. 2021, 143, 091204. [CrossRef]

35. Brunone, B.; Meniconi, S.; Capponi, C. Numerical analysis of the transient pressure damping in a single polymeric pipe with a leak. Urban Water J. 2018, 15, 760-768. [CrossRef]

36. Bergant, A.; Tijsseling, A.S.; Vítkovský, J.P.; Covas, D.I.C.; Simpson, A.R.; Lambert, M.F. Parameters affecting water-hammer wave attenuation, shape and timing-Part 1: Mathematical tools. J. Hydraul. Res. 2008, 46, 373-381. [CrossRef]

37. Evangelista, S.; Leopardi, A.; Pignatelli, R.; de Marinis, G. Hydraulic Transients in Viscoelastic Branched Pipelines. J. Hydraul. Eng. 2015, 141, 04015016. [CrossRef]

38. Duan, H.-F.; Ghidaoui, M.; Lee, P.J.; Tung, Y.-K. Unsteady friction and visco-elasticity in pipe fluid transients. J. Hydraul. Res. 2010, 48, 354-362. [CrossRef]

39. Pal, S.; Hanmaiahgari, P.R.; Karney, B.W. An Overview of the Numerical Approaches to Water Hammer Modelling: The Ongoing Quest for Practical and Accurate Numerical Approaches. Water 2021, 13, 1597. [CrossRef]

40. Bertaglia, G.; Ioriatti, M.; Valiani, A.; Dumbser, M.; Caleffi, V. Numerical methods for hydraulic transients in visco-elastic pipes. J. Fluids Struct. 2018, 81, 230-254. [CrossRef]

41. Bogdevičius, M.; Karpenko, M.; Bogdevičius, P. Determination of rheological model coefficients of pipeline composite material layers based on spectrum analysis and optimization. J. Theor. Appl. Mech. 2021, 265-278. [CrossRef]

42. Weinerowska-Bords, K. Viscoelastic Model of Waterhammer in Single Pipeline-Problems and Questions. Arch. Hydro-Eng. Environ. Mech. 2006, 53, 21.

43. Weinerowska-Bords, K. Alternative Approach to Convolution Term of Viscoelasticity in Equations of Unsteady Pipe Flow. J. Fluids Eng. 2015, 137, 054501. [CrossRef] 